Research Article

\title{
Freezing Temperature Field of FSPR under Different Pipe Configurations: A Case Study in Gongbei Tunnel, China
}

\author{
Yin Duan $\mathbb{D}^{1,2}$, Chuanxin Rong $\mathbb{D}^{1,2}$ Hua Cheng, ${ }^{1,2}$ Haibing Cai $\mathbb{D},{ }^{1,2}$ and Wei Long $\mathbb{D}^{1,2}$ \\ ${ }^{1}$ State Key Laboratory of Mining Response and Disaster Prevention and Control in Deep Coal Mine, Huainan, China \\ ${ }^{2}$ School of Civil Engineering and Architecture, Anhui University of Science and Technology, Huainan 232001, China
}

Correspondence should be addressed to Chuanxin Rong; chxrong@aust.edu.cn

Received 26 March 2021; Accepted 22 July 2021; Published 2 August 2021

Academic Editor: Zhang Dongmei

Copyright (c) 2021 Yin Duan et al. This is an open access article distributed under the Creative Commons Attribution License, which permits unrestricted use, distribution, and reproduction in any medium, provided the original work is properly cited.

As a new tunnel presupport construction technology, the freeze-sealing pipe roof method (FSPR) has been successfully applied to the Gongbei Tunnel Project for the first time in China. To overcome the practical difficulties of this new method in the freezing construction process, such as welding difficulties of the profiled freezing tube, refrigerant leakage, and long construction period, based on the principle of an equal cooling capacity, an improved design of freezing tube was proposed. By designing three different pipe configurations and using scaled model tests and numerical simulation, the feasibility of the improvement and the difference in the freezing temperature field were studied. The research results show that the improved design with double circular freezing tubes exhibited a lower temperature and a higher cooling rate during the test, and the time required to meet the freezing design requirements was significantly shortened. Finally, a composite structure of "pipe roof and frozen soil curtain" with a better carrying capacity and water sealing performance was formed. It was recommended to strengthen the temperature monitoring at the pipe wall in the preliminary stage of the freezing construction to ensure the water sealing effect between the pipes. In the later stage, attention should be paid to monitoring the thickness of the frozen curtain and reducing excessive frost heave through technical means such as cooling capacity control. The improvement and configurations proposed in this research could effectively replace profiled freezing tubes in the original project, better adapt to horizontal freezing projects of similar curved tunnels, achieve the freezing goal faster, and provide a reference for the promotion of the FSPR.

\section{Introduction}

The construction and expansion of urban underground structures, especially underground traffic tunnels, is the key to alleviating the pressure on urban surface traffic, promoting urban economic development, improving urban ecological environments and urban structures, and achieving sustainable development $[1,2]$. Short-distance urban underground largesection traffic tunnels mostly adopt shallow-buried and concealed construction methods $[3,4]$. In the southern and coastal areas of China, this method mainly faces the problem of complex saturated soft soil layers. As a common presupport method in these areas, the pipe roof method (PRM) uses a combination of multiple steel jacking pipes as the load-bearing structure and installs water-stop locks between the jacking pipes to achieve the goal of controlling ground subsidence and sealing water [5-9]. The artificially ground freezing method (AGF) has also been widely used in more than 220 municipal and subway freezing projects in the water-bearing soft ground of China [10-15].

As shown in Figure 1, the Gongbei Tunnel serves as a key project for the Zhuhai connecting line of the Hong KongZhuhai-Macao Bridge, which passes through the Gongbei Port of Zhuhai City. It is a typical shallow-buried tunnel with a length of $255 \mathrm{~m}$, a buried depth of $4-5 \mathrm{~m}$, and a crosssectional area of $345 \mathrm{~m}^{2}$, and its design line consists of a gentle curve and a circular curve $(R=890 \mathrm{~m})[16,17]$. The geology of the tunnel site is extremely complex, which is composed of a large number of unevenly developed waterrich soft sandy soil layers and silt clay layers. Numerous ground buildings have been developed along the line, most of which were pile foundations, and the closest distance 


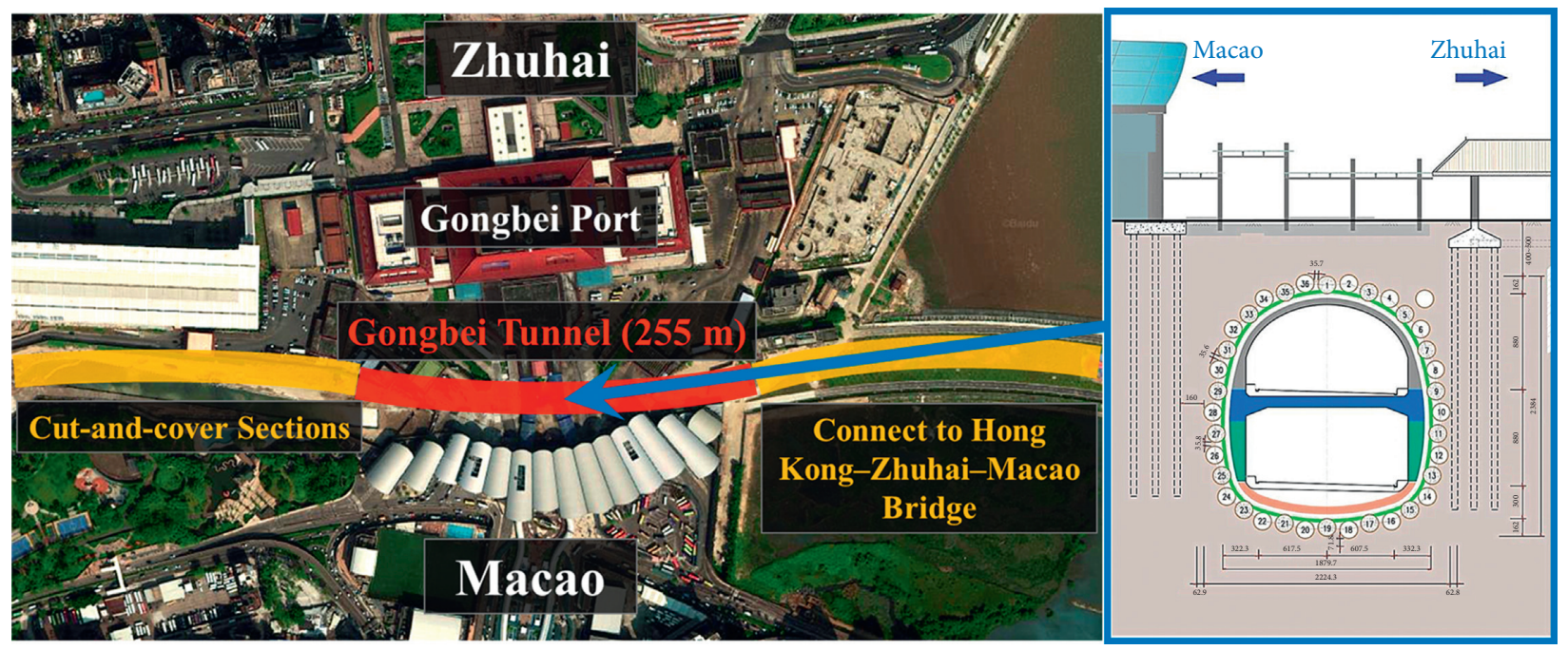

FIgURE 1: Schematic diagram of the Gongbei Tunnel.

between the pipe roof and the structural pile foundation was only $0.46 \mathrm{~m}$, making the tunnel construction extremely difficult. The pipe roof method has poor adaptability to curved tunnels and cannot guarantee the water sealing effect between the jacking pipes, leading to higher construction risks. The artificially ground freezing method also has the effect of frost heaving and thaw settlement of the ground, causing an adverse impact on nearby structures of the tunnel. After repeated demonstrations, the freeze-sealing pipe roof method (FSPR) which combines the advantages of the pipe roof method and the artificially ground freezing method has been proposed. The principle of this new method is that, firstly, several sections of large-diameter and closely arranged steel pipes were jacked into the stratum to form a pipe roof, and then the artificially ground freezing was carried out by installing freezing tubes inside the pipe wall to form a certain thickness of frozen soil curtain around the pipe roof, finally forming a supporting system with both bearing capacity and water sealing performance.

As in Figure 2, 18 concrete pipes (filled with concrete) and 18 hollow pipes with a diameter of $1.6 \mathrm{~m}$ were alternately arranged around the tunnel excavation section, and the average distance between jacking pipes was about $357 \mathrm{~mm}$. The circular freezing tubes were installed on the left and right sides of the inner wall of the concrete pipes (oddnumbered pipes) to freezing soil layers, and the limiting tube in the concrete pipe controls the thickness of frozen soil by circulating hot saltwater in the later period of freezing. The profiled freezing tubes (made of $125 \mathrm{~mm} \times 125 \mathrm{~mm} \times 8 \mathrm{~mm}$ angle iron) were directly welded on the inner wall of the hollow pipes (even-numbered pipes) to strengthen freezing between the pipes (Figure 3). These hollow pipes were not filled with concrete and were mainly used as passages for freezing monitoring during the construction process. To ensure the water sealing effect while avoiding excessive frost heave, the thickness range of the frozen soil curtain was set to $2-2.6 \mathrm{~m}$. The actual freezing time established by the freezing construction plan was 180 days, of which the active freezing period lasted for the first 90 days.
Based on the engineering characteristics of the Gongbei Tunnel, $\mathrm{Hu}$ et al. [18, 19] established a temperature field calculation model for the FSPR through theoretical derivations and numerical simulations and obtained an analytical solution of the steady-state temperature field. Moreover, the feasibility of this method has been verified through model tests [20, 21] and field measurements [22]. Ren et al. [23] performed numerical simulations and largescale model tests to demonstrate the feasibility and reliability of the fine dynamic control freezing and sealing water design scheme. Ji et al. [24] proposed that it is necessary to carry out further investigations on technical issues of the FSPR, such as long-distance zoned horizontal freezing ground reinforcement mechanism, freezing parameters, and modes. Kang et al. [25] conducted numerical simulations on the excavation of the Gongbei Tunnel and pointed out that the change of the temperature field was the key factor for predicting the frozen wall thickness. Lu et al. [26] analyzed and predicted the overall temperature field of a freezing pipe circular arrangement and the change of the freezing curtain thickness with time through finite element numerical simulations. Zhang et al. [27] predicted the soil temperature change and surface frost heave displacement during an artificial freezing process based on a thermomechanical coupling method and compared the effects of two methods of controlling ground frost heave: soil pregrouting around the pipe roof and the application of limiting tubes. Ren et al. [28] analyzed and verified the pipe combination method through field temperature measurements based on the engineering design plan.

The abovementioned research played an important role in promoting the theoretical development and application of the FSPR. However, some practical problems were still encountered during the freezing construction period. In particular, the installation of the profiled freezing tube requires a large amount of overhead and arc welding, and all the works need to be completed in a narrow space inside the jacking pipe. These excessive welding difficulties cannot guarantee the installation quality and often lead to cracks 


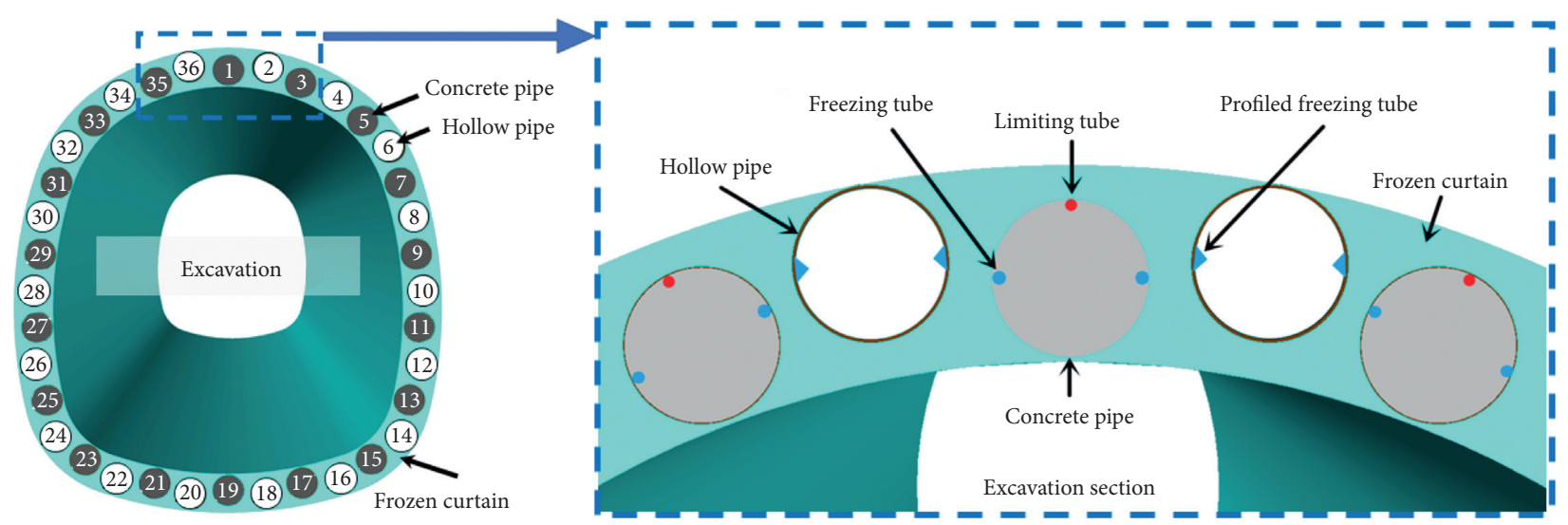

FIgURe 2: Principle diagram of FSPR method designed for Gongbei Tunnel.
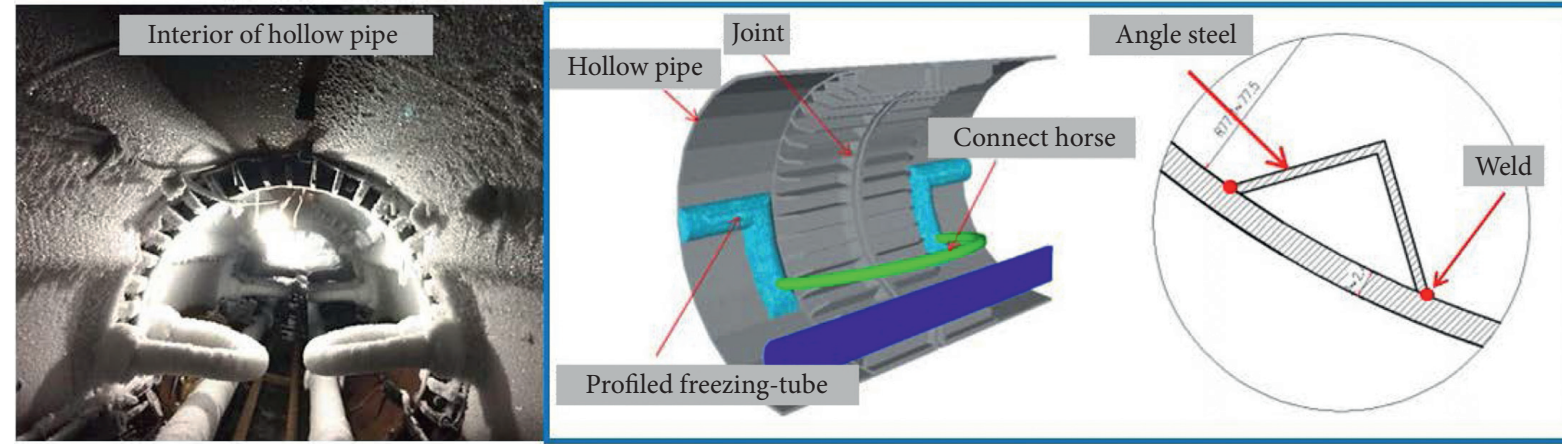

FIgURE 3: Diagrammatic sketch of hollow pipe with profiled freezing tube.

and refrigerant leakage, resulting in high maintenance costs. Furthermore, it not only affected the construction schedule but also brought about working environment problems, such as construction thermal disturbance and safety hazards.

In this study, to overcome the practical difficulties of FSPR in the freezing construction process, we took jacking pipes and freezing tubes as the research objects and proposed an improved design for the profiled freezing tubes based on previous research $[29,30]$. The feasibility of the improvement and the difference in the freezing temperature field under different pipe configurations during the active freezing period was investigated through scaled model tests and numerical simulations to provide a certain reference for the promotion of this new construction method.

\section{Scaled Model Test and Process}

2.1. Scaling Laws and Test Materials. Considering different test conditions, the geometric scaling law was first determined as $C_{l}=1 / 10$. Other related scaling laws were obtained based on the Kosovich criterion and the Fourier criterion (Table 1) [31-33]. The test soil layer material was selected according to project site conditions. The diameters of the jacking pipe and the freezing tube, velocity and flow, and the physical parameters of the test materials through laboratory tests are presented in Tables $2-4$, respectively.
2.2. Model Design and Test System. Three types of jacking pipes were designed in this test: one concrete pipe and two hollow pipes. The concrete pipe was made by installing a freezing tube on each horizontal side of the inner wall of the steel pipe and filling it with C30 fine aggregate concrete. One of the hollow pipes has the same structure as the engineering prototype, and the other one is an improved design based on the principle of equal cooling capacity, which uses cement mortar (made of Ordinary Portland Cement, sand, and water) to wrap and fix the circular freezing tubes on the inner wall of the hollow pipe, instead of the welded profiled freezing tubes in the prototype (Figure 4). Due to the complexity of the pipe roof form in the actual project, it was appropriately simplified in the current test. Some of the concrete pipes and the hollow pipes were taken for the horizontal arrangement to design three different pipe configurations (Figure 5).

(1) Configuration A: The combination of a concrete pipe and a hollow pipe (including the profiled freezing tubes), and this configuration was consistent with the engineering prototype.

(2) Configuration B: The combination of a concrete pipe and a hollow pipe (including the improved double circular freezing tubes).

(3) Configuration C: The combination of two concrete pipes and three hollow pipes (including improved double circular freezing tubes). 
TABLe 1: Scaling laws.

\begin{tabular}{lccccccc}
\hline $\begin{array}{l}\text { Scaling } \\
\text { parameter }\end{array}$ & $\begin{array}{c}\text { Geometry } \\
(\mathrm{mm})\end{array}$ & $\begin{array}{c}\text { Temperature } \\
\left({ }^{\circ} \mathrm{C}\right)\end{array}$ & $\begin{array}{c}\text { Thermal capacity } \\
\left(\mathrm{J} \cdot \mathrm{kg}^{-1} \cdot \mathrm{K}\right)\end{array}$ & $\begin{array}{c}\text { Thermal conductivity } \\
\left(\mathrm{W} \cdot \mathrm{m}^{-1} \cdot \mathrm{K}^{-1}\right)\end{array}$ & $\begin{array}{c}\text { Velocity of flow } \\
(\mathrm{m} / \mathrm{min})\end{array}$ & $\begin{array}{c}\text { Rate of flow } \\
(\mathrm{m} / \mathrm{h})\end{array}$ & $\begin{array}{c}\text { Time } \\
(\mathrm{h})\end{array}$ \\
\hline Scaling law & $1 / 10$ & 1 & 1 & 1 & 10 & $1 / 10$ \\
\hline
\end{tabular}

TABle 2: Diameters of jacking pipe and freezing tube.

\begin{tabular}{lcc}
\hline Diameter & Prototype $(\mathrm{mm})$ & Model $(\mathrm{mm})$ \\
\hline Jacking pipe & 1600 & 160 \\
Freezing tube & 80 & 8 \\
\hline
\end{tabular}

TABLe 3: Velocity and flow.

\begin{tabular}{lcc}
\hline Parameter $($ single-tube $)$ & Prototype & Model \\
\hline Flow rate $\left(\mathrm{m}^{3} / \mathrm{h}\right)$ & 5 & 0.5 \\
Flow velocity $(\mathrm{m} / \mathrm{min})$ & 16.6 & 166 \\
\hline
\end{tabular}

TABle 4: Physical parameters of test materials.

\begin{tabular}{|c|c|c|c|c|c|c|c|c|}
\hline \multirow{2}{*}{$\begin{array}{l}\text { Material } \\
\text { Saturated sand }\end{array}$} & \multicolumn{2}{|c|}{$\begin{array}{l}\text { Density } \\
\left(\mathrm{kg} \cdot \mathrm{m}^{-3}\right)\end{array}$} & \multicolumn{2}{|c|}{$\begin{array}{l}\text { Thermal capacity } \\
\left(\mathrm{J} \cdot \mathrm{kg}^{-1} \cdot \mathrm{K}\right)\end{array}$} & \multicolumn{2}{|c|}{$\begin{array}{l}\text { Thermal conductivity } \\
\left(\mathrm{W} \cdot \mathrm{m}^{-1} \cdot \mathrm{K}^{-1}\right)\end{array}$} & \multirow{2}{*}{$\begin{array}{c}\text { Water content }(\%) \\
40.29\end{array}$} & \multirow{2}{*}{$\begin{array}{c}\text { Freezing point }\left({ }^{\circ} \mathrm{C}\right) \\
-0.5\end{array}$} \\
\hline & $\begin{array}{c}\rho \\
1436\end{array}$ & $\begin{array}{c}\rho_{\text {sat }} \\
2054\end{array}$ & $\begin{array}{c}\text { Unfrozen } \\
1370\end{array}$ & $\begin{array}{c}\text { Frozen } \\
1070\end{array}$ & $\begin{array}{c}\text { Unfrozen } \\
1.48\end{array}$ & $\begin{array}{c}\text { Frozen } \\
1.80\end{array}$ & & \\
\hline C30 concrete & \multicolumn{2}{|c|}{2455} & \multicolumn{2}{|c|}{920} & \multicolumn{2}{|c|}{1.64} & - & - \\
\hline Cement mortar & \multicolumn{2}{|c|}{1910} & \multicolumn{2}{|c|}{845} & \multicolumn{2}{|c|}{1.29} & - & - \\
\hline Steel pipe & \multicolumn{2}{|c|}{7840} & \multicolumn{2}{|c|}{319} & \multicolumn{2}{|c|}{62} & - & - \\
\hline Air & \multicolumn{2}{|c|}{1.28} & \multicolumn{2}{|c|}{1005} & \multicolumn{2}{|c|}{0.02} & - & - \\
\hline
\end{tabular}

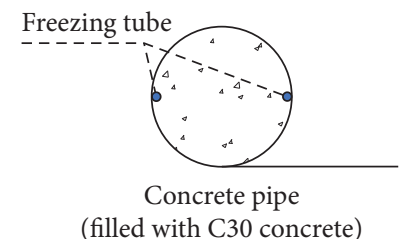

(filled with C30 concrete)

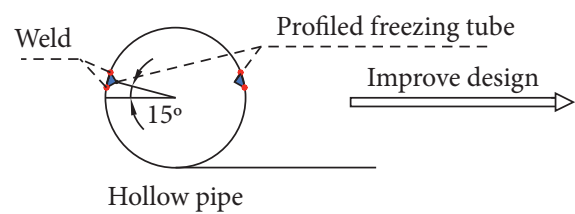

(including profiled freezing tube)

(including the improved double circular freezing tube)

FIgURE 4: Three types of jacking pipes.

The horizontal distance between adjacent pipes and the distance between adjacent measurement points were both $50 \mathrm{~mm}$. In Configurations $\mathrm{A}$ and $\mathrm{B}$, temperature measurement points were arranged on the midline between the two pipes and in the vertical and horizontal directions of the hollow pipe. In Configuration C, considering that the pipes alternately formed the pipe roof, three rows of temperature measurement points were set in the vertical direction. All the red points in Figure 5 were control points, which were used to monitor whether the test results complied with the freezing design requirements.

The size of the model box was $1200 \mathrm{~mm} \times 3900 \mathrm{~mm} \times 1500 \mathrm{~mm}(H \times W \times L)$, which was welded by $6 \mathrm{~mm}$ thick steel plates and divided into three test areas. Insulation materials were laid on the inner wall of the box, and partitions were provided in adjacent test areas. All the jacking pipes were installed horizontally in the center of the box, and the height of the pipe center from the ground was $600 \mathrm{~mm}$ (Figure 6).
Two temperature monitoring systems were designed for this test (Figure 7(a)). A TML TDS-602 data logger with thermocouple sensors was used as the main monitoring system (Figure 7(b)) and the test data were based on it. The accuracy of the sensor was $\pm 0.1^{\circ} \mathrm{C}$ and the range was from $-80^{\circ} \mathrm{C}$ to $+200^{\circ} \mathrm{C}$. A CW -500 digital thermometer was used as the auxiliary monitoring system, which performed auxiliary acquisition during the test to guarantee the authenticity of the data. The plane of the measurement points of these two systems was symmetrical along the horizontal centerline of the model (Figure 7(a)). Each freezing tube had an independent valve and was connected with the main inlet and return pipes of the refrigeration system (Figure $7(\mathrm{c})$ ). An SKLD-80F electromagnetic flowmeter was installed on the main freezing tube to monitor the total flow. Following the freezing construction organization of the Gongbei Tunnel, the temperature of the freezing system was controlled in the range of -25 to $-28^{\circ} \mathrm{C}$; hence, the freezing system temperature of this test was set to $-25^{\circ} \mathrm{C}$. 


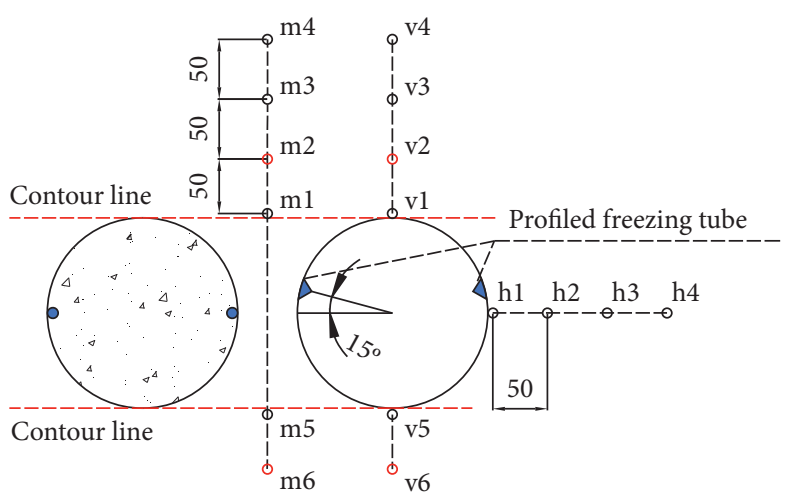

(a)

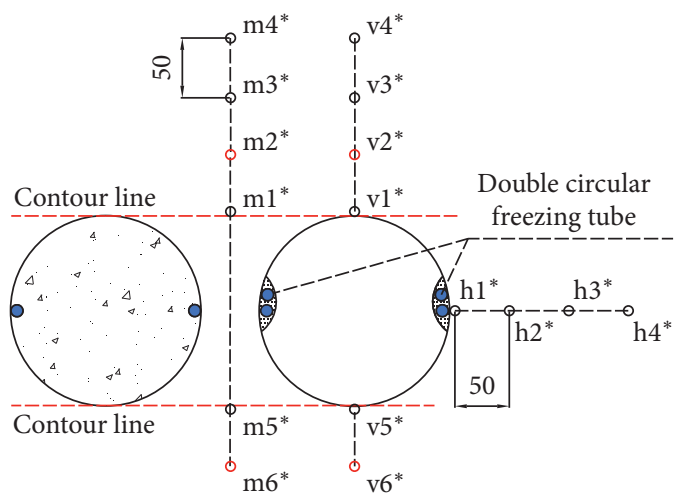

(b)
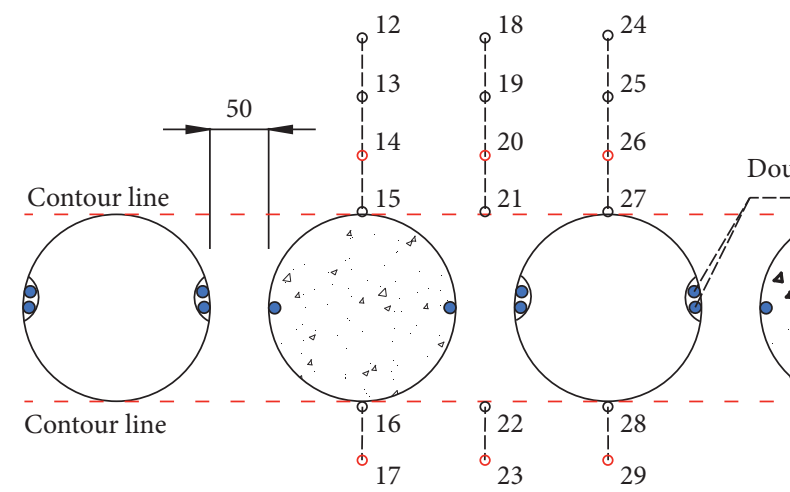

Double circular freezing tube

(c)

Figure 5: Three different pipe configurations with temperature measurement points ( $\mathrm{mm}$ ): (a) Configuration A. (b) Configuration B. (c) Configuration C.

\subsection{Test Process}

(1) Combining the active freezing period of the project (90 days) and the time scaling law (1/100), the converted freezing time of this test was set to 0.9 days (about 21 hours).

(2) Turn on the refrigeration system and reduce the saltwater temperature to the design value $\left(-25^{\circ} \mathrm{C}\right)$.

(3) When the refrigeration system began to circulate, one-time freezing was conducted in all test areas. The system automatically monitors and collects the temperature data until the end of the test.

(4) The average thickness of the frozen soil curtain specified in the Gongbei Tunnel's freezing construction design data ranges from 2 to $2.6 \mathrm{~m}$. Considering the geometric scaling law $C_{l}=1 / 10$, it can be obtained that the freezing target of this test is to make the frozen wall thickness reach $260 \mathrm{~mm}$, which means that the temperature of the red points in Figure 5 has reached the freezing point $\left(-0.5^{\circ} \mathrm{C}\right)$.

\section{Test Results and Discussion}

3.1. Contrast Analysis of Improved Design. Figures 8 and 9 display the "temperature-time" curves at midline points and vertical line points in Configurations $A$ and $B$, respectively. The blue horizontal dotted line in each figure represents the freezing point $\left(-0.5^{\circ} \mathrm{C}\right)$ baseline. In Tables $5-7, T_{0}$ and $T_{21}$ represent the initial temperature and final temperature of the test, respectively, $V$ represents the average cooling rate in 21 hours, and $\Delta T$ and $\Delta t$ represent temperature difference and time difference, respectively. It was noticeable that all curves manifested a general trend of decreasing first and then stabilizing. The curves of the symmetrical points basically coincide, and the temperature of the points on the contour line (Figure 5) was the lowest. The temperature at each point dropped sharply in the first 5 hours; however, the slope of the curve for Configuration $\mathrm{B}$ was greater. At $12 \mathrm{~h}$, the temperature of $\mathrm{m} 1$ and $\mathrm{m} 5$ in Configuration A reached the freezing point, indicating that the thickness of the frozen soil between the pipes reached $160 \mathrm{~mm}$; however, the corresponding time in Configuration B was only 5 hours. The temperatures at $\mathrm{m} 2^{*}$ and $\mathrm{m} 6^{*}$ had reached the freezing point at $14 \mathrm{~h}$ ( 7 hours earlier than Configuration A), which indicates that the thickness of the frozen soil between the two pipes reached $260 \mathrm{~mm}$, and the freezing time was shortened by $33.3 \%$. At $21 \mathrm{~h}$, the average temperature at $\mathrm{m} 2 *$ and $\mathrm{m} 6^{*}$ was $-4.4^{\circ} \mathrm{C}$, which was $3.75^{\circ} \mathrm{C}$ lower than that of $\mathrm{m} 2$ and $\mathrm{m} 6$, and the average cooling rate increased by $25.5 \%$ (Table 5).

Compared with Configuration $\mathrm{A}$, the temperatures at control points $\mathrm{v} 2 *$ and $\mathrm{v} 6^{*}$ in Configuration $\mathrm{B}$ had reached the freezing point at $16 \mathrm{~h}$, and the average temperature was reduced by $4.65^{\circ} \mathrm{C}$ at $21 \mathrm{~h}$, and the average cooling rate increased by $34.1 \%$ (Table 6 ). The temperature at $\mathrm{h} 2^{*}$ had reached the freezing point at $10 \mathrm{~h}$ ( 9 hours earlier than the 


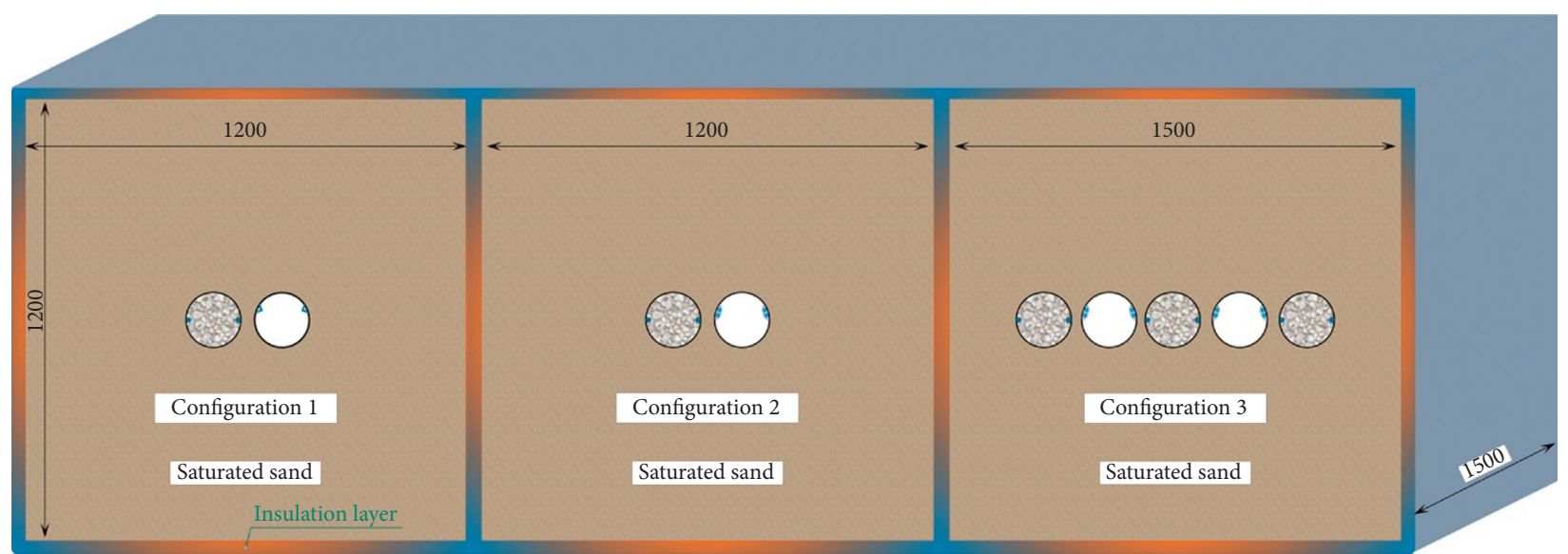

Figure 6: Test model box.

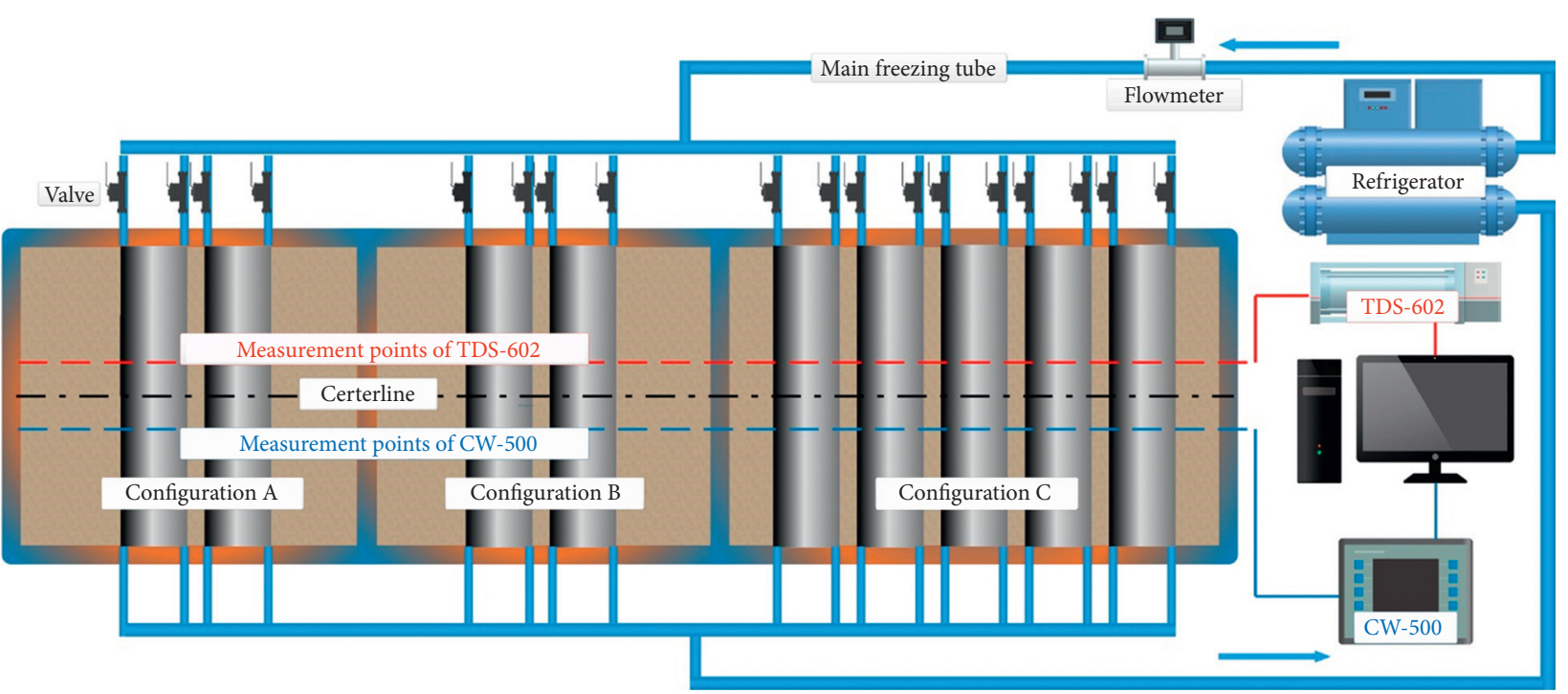

(a)

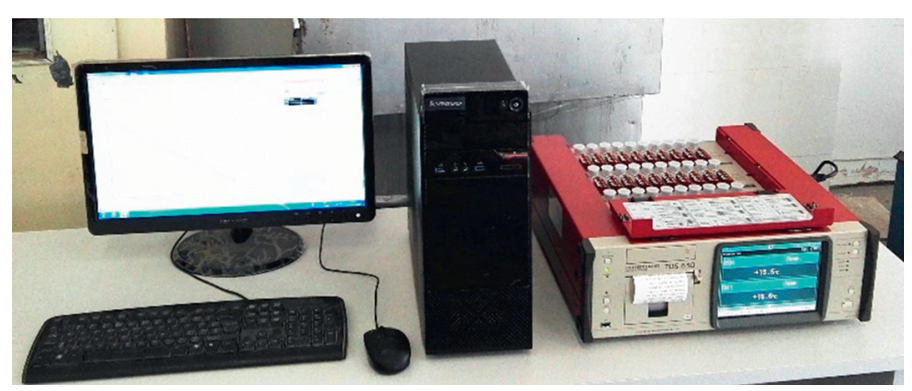

(b)

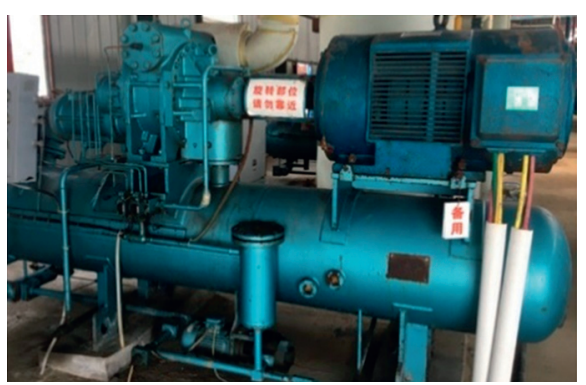

(c)

FIGURE 7: Layout of the test system: (a) Schematic plan of the test system. (b) TDS-602 data logger. (c) Freezing system.

time at h2, corresponding to a reduction of 47\%) (Table 7). At $21 \mathrm{~h}$, the temperature at $\mathrm{h} 2{ }^{*}$ was $3^{\circ} \mathrm{C}$ lower than that at $\mathrm{h} 2$, and the average cooling rate increased by $13 \%$, indicating that the improved design enhanced the vertical and horizontal freezing effect of the hollow pipe.
Although both configurations ultimately met test design requirements, it is obvious that the improved design yielded superior results and reflected a shorter freezing time and a higher cooling rate. The remaining points also supported these observations. 


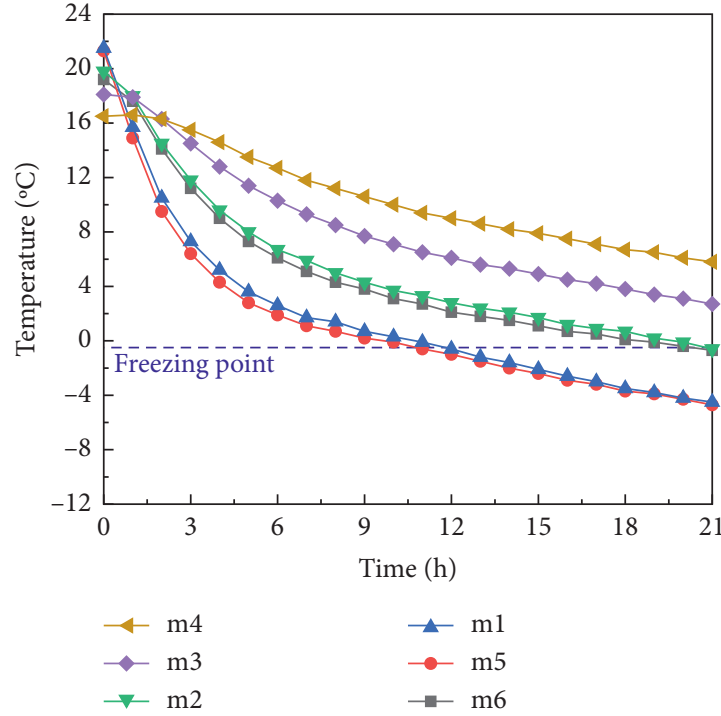

(a)

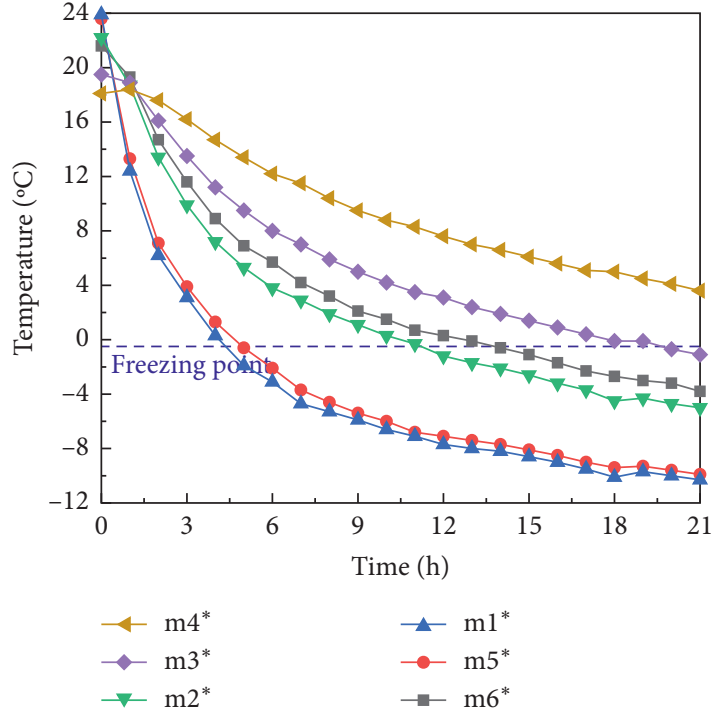

(b)

Figure 8: Temperature-time curves at midline points: (a) Configuration A. (b) Configuration B.

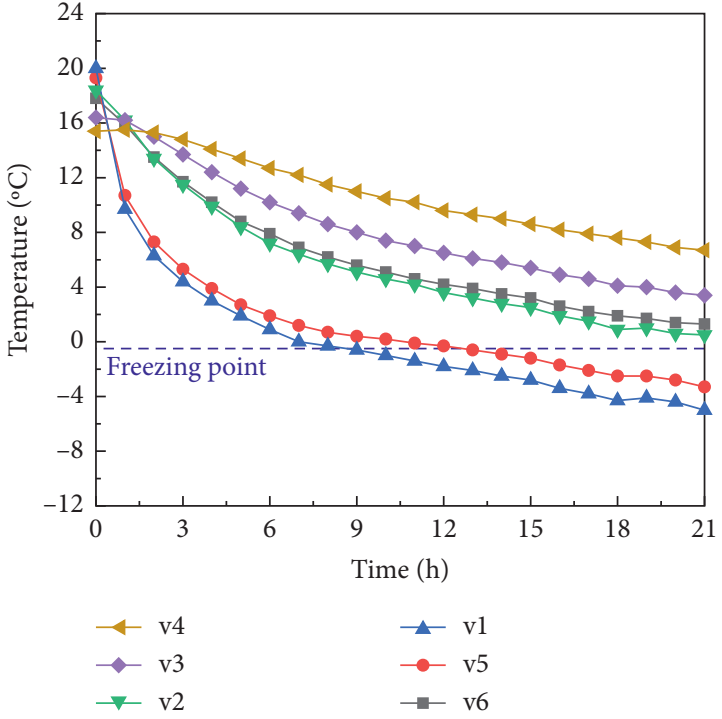

(a)

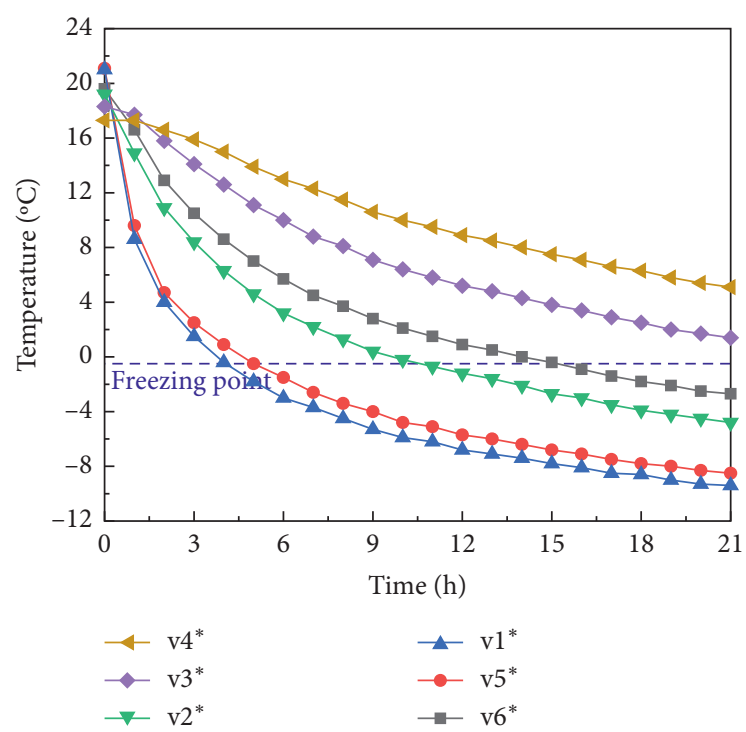

(b)

Figure 9: Temperature-time curves along the vertical line of hollow pipes: (a) Configuration A. (b) Configuration B.

3.2. Analysis of Test Results Based on Improved Pipe Roof. It was clear from Figure 10(a) that, in comparison to Configuration $\mathrm{B}$, as Configuration $\mathrm{C}$ used multiple jacking pipes to form the "pipe roof," the freezing effect was further improved in the middle and late stages of the test. The temperature curves at $\mathrm{m} 1^{*}$ and 21 measurement points coincided in the first four hours, indicating that, in the early freezing stage, temperature fields between jacking pipes changed in the same degree and the "group pipe effect" was not yet obvious. With the prolonged freezing time, the temperature curve at the measurement point 21 dropped further, and the "group pipe effect" gradually improved the freezing effect. At the end of the test, the temperatures at $\mathrm{m}^{*}$ and 21 measurement points were $-10.3^{\circ} \mathrm{C}$ and $-13^{\circ} \mathrm{C}$, respectively, and the other points conformed to the above rules.

It was observable from Figure 10(b) and Table 8 that the temperature curve at each measurement point $50 \mathrm{~mm}$ above the pipe contour line in Configuration $\mathrm{C}$ followed the same variation trend. In comparison to Configuration $\mathrm{B}$, the "group pipe effect" in Configuration $\mathrm{C}$ was more evident. Temperatures at all measurement points dropped below the 
TABle 5: Contrast of temperature data of control points at midline.

\begin{tabular}{lcccccc}
\hline Measuring point & $T_{0}\left({ }^{\circ} \mathrm{C}\right)$ & $T_{21}\left({ }^{\circ} \mathrm{C}\right)$ & $\Delta T\left({ }^{\circ} \mathrm{C}\right)$ & $V\left({ }^{\circ} \mathrm{C} / \mathrm{h}\right)$ & Time of temperature below freezing point $(\mathrm{h})$ & $\Delta t(\mathrm{~h})$ \\
\hline $\mathrm{m} 2$ & 19.8 & -0.6 & -4.4 & -0.97 & 21 & 12 \\
$\mathrm{~m} 2^{*}$ & 22.2 & -5.0 & & -1.30 & 21 & -9 \\
$\mathrm{~m} 6$ & 19.2 & -0.7 & -3.1 & -1.03 & 14 & -7 \\
$\mathrm{~m} 6$ & 21.6 & -3.8 & & -1.21 & \\
\hline
\end{tabular}

TABLE 6: Contrast of temperature data of control points at vertical line.

\begin{tabular}{lcccccc}
\hline Measuring point & $T_{0}\left({ }^{\circ} \mathrm{C}\right)$ & $T_{21}\left({ }^{\circ} \mathrm{C}\right)$ & $\Delta T\left({ }^{\circ} \mathrm{C}\right)$ & $V\left({ }^{\circ} \mathrm{C} / \mathrm{h}\right)$ & Time of temperature below freezing point $(\mathrm{h})$ & - \\
\hline v2 & 18.4 & 0.5 & -5.3 & -0.85 & 12 & - \\
v2 & 19.2 & -4.8 & & -1.14 & - \\
v6 & 17.8 & 1.3 & -4.0 & -0.79 & 16 \\
v6 & 19.6 & -2.7 & -1.06 & - \\
\hline
\end{tabular}

TABLE 7: Contrast of temperature data at horizontal direction.

\begin{tabular}{lcccccc}
\hline Measuring point & $T_{0}\left({ }^{\circ} \mathrm{C}\right)$ & $T_{21}\left({ }^{\circ} \mathrm{C}\right)$ & $\Delta T\left({ }^{\circ} \mathrm{C}\right)$ & $V\left({ }^{\circ} \mathrm{C} / \mathrm{h}\right)$ & Time of temperature below freezing point $(h)$ & $\Delta t(\mathrm{~h})$ \\
\hline $\mathrm{h} 2$ & 19.9 & -1.2 & -5.4 & -1.00 & 19 & 10 \\
$\mathrm{~h} 2{ }^{*}$ & 19.6 & -4.2 & & -1.13 & 9 \\
\hline
\end{tabular}

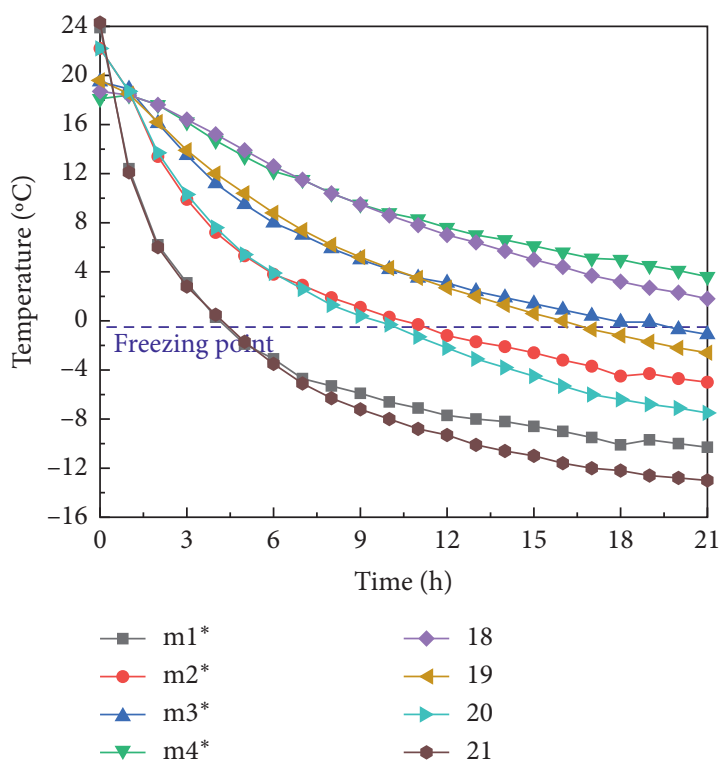

(a)

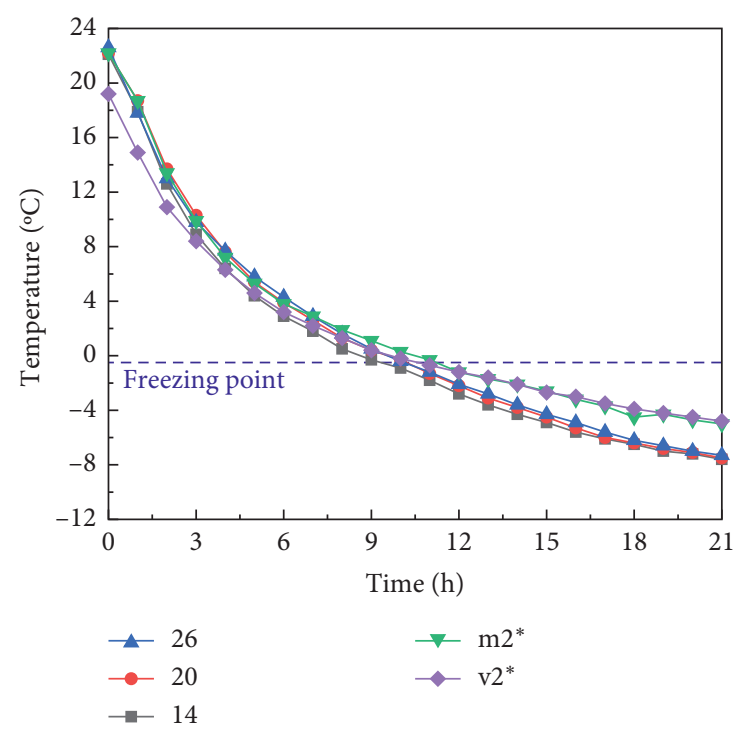

(b)

Figure 10: Comparison of "temperature-time" curves at measurement points in Configurations B and C. (a) Midline points between the pipes in Configurations $\mathrm{B}$ and $\mathrm{C}$ and (b) points at $50 \mathrm{~mm}$ above the pipe contour line in Configurations $\mathrm{B}$ and $\mathrm{C}$.

freezing point at $11 \mathrm{~h}$, and the time was shortened by 1 hour. Moreover, the average temperature at $21 \mathrm{~h}$ was $-7.5^{\circ} \mathrm{C}$, which was about $2.6^{\circ} \mathrm{C}(53 \%)$ lower than that of Configuration $\mathrm{B}$, and the average cooling rate also increased by $16 \%$. Therefore, by adopting the pipe roof form consisting of a hollow pipe with improved double circular freezing tubes and a concrete pipe, a frozen soil curtain with a certain thickness quickly formed in the soil layer, and the freezing target can be achieved earlier.

\section{Numerical Simulation Results and Discussion}

4.1. Model Establishment. Numerical models were established for the three pipe configurations to study the development law and the differences of freezing temperature field. Taking Configuration $\mathrm{C}$ as an example, the two-dimensional temperature field of the test model was simulated in COMSOL Multiphysics ${ }^{\circledR}$ v. 5.4 (Figure 11). The 
TABLE 8: Temperature data at measurement point $50 \mathrm{~mm}$ above the contour line in Configurations B and C.

\begin{tabular}{lcccc}
\hline Measuring point & $T_{0}\left({ }^{\circ} \mathrm{C}\right)$ & $T_{21}\left({ }^{\circ} \mathrm{C}\right)$ & $V\left({ }^{\circ} \mathrm{C} / \mathrm{h}\right)$ & Time of temperature below freezing point $(\mathrm{h})$ \\
\hline 14 & 22.1 & -7.6 & -1.41 & 10 \\
20 & 22.2 & -7.5 & -1.41 & 11 \\
26 & 22.6 & -7.3 & -1.42 & 11 \\
$\mathrm{~m}^{*}$ & 22.2 & -5 & -1.30 & 12 \\
$\mathrm{v}^{*}$ & 19.2 & -4.8 & -1.14 & 12 \\
\hline
\end{tabular}

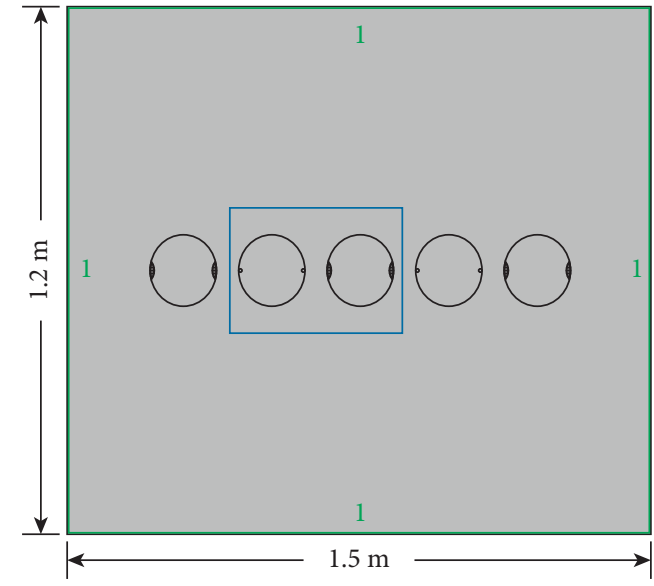

(a)

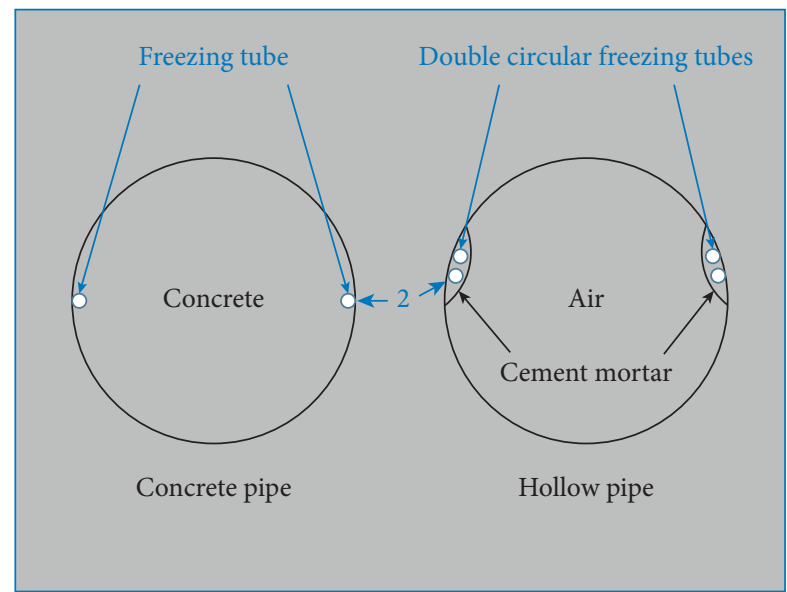

(b)

FIGURE 11: Numerical model of Configuration C.

calculation module adopted the porous medium heat transfer module, which can effectively simulate the heat transfer phenomena in the soil [34-36]. The computational domain grid system used nonstructural triangular elements, and the grid density was higher near the steel pipes and the freezing tubes (Figure 12). The minimum element size, average element mass, and minimum element mass of the numerical model were $0.42 \mathrm{~mm}, 0.8289$, and 0.04317 , respectively, indicating that the mesh element quality was good and the calculation results were convergent [37]. The numerical model had two boundaries (Figure 11): the first one was the soil layer boundary, which acted as an insulation layer, and the initial temperature of the soil layer was set to $20^{\circ} \mathrm{C}$; and the second one was the freezing tube wall $\left(-25^{\circ} \mathrm{C}\right)$, which followed the Dirichlet boundary condition.

The comparison between the simulation data and the test data of selected measurement points in Figure 13 shows that the numerical results are in good agreement with the test, which means that the numerical simulation method used in this paper has good accuracy. Therefore, it can conduct indepth and comprehensive research on the variation law of freezing temperature field and the development of frozen soil curtain.

4.2. Validation of Improved Results. Figures 14 and 15 compare the 21-hour freezing temperature field distributions and the frozen soil wall thicknesses at different positions in Configurations $\mathrm{A}$ and $\mathrm{B}$, respectively. As the freezing tubes were near the horizontal direction of the pipes, the temperature in the horizontal direction was lower than that in the vertical direction, and the shape of the isotherm at a far distance was approximately elliptical. The average thicknesses of the frozen wall formed between the two pipes in Configurations A and B were $252 \mathrm{~mm}$ and $281 \mathrm{~mm}$, respectively, which means that a reliable water sealing structure between the pipes was formed. However, in comparison to Configuration $\mathrm{A}$, the average thickness of the frozen soil wall on the vertical line of the hollow pipe, the vertical line of the concrete pipe, and between the two pipes increased by $20 \%, 7 \%$, and $12 \%$ in Configuration $\mathrm{B}$, respectively.

4.3. Discussion on Development and Distribution Law of Freezing Temperature Field Based on Improved Design. Figure 16(a) exhibits the temperature field cloud diagram of Configuration $\mathrm{C}$ at $3 \mathrm{~h}$, and the black line represented the boundary of the frozen soil wall. As the distance between the pipes was very small and the freezing tubes were close to the horizontal position on both sides of the pipes, the frozen soil wall of a certain thickness was initially formed between the pipes. Due to the alternating arrangement of the concrete pipes and hollow pipes, the shape of the frozen soil wall between the pipes was asymmetric, and the thickness near the concrete pipe was slightly larger, and the overall average thickness was about $123.2 \mathrm{~mm}$. Although the frozen soil wall had a role in sealing water to a certain extent, it was limited by its thickness; thus, cracks and water flow passages may have appeared at the junction of frozen soil and the pipe wall 


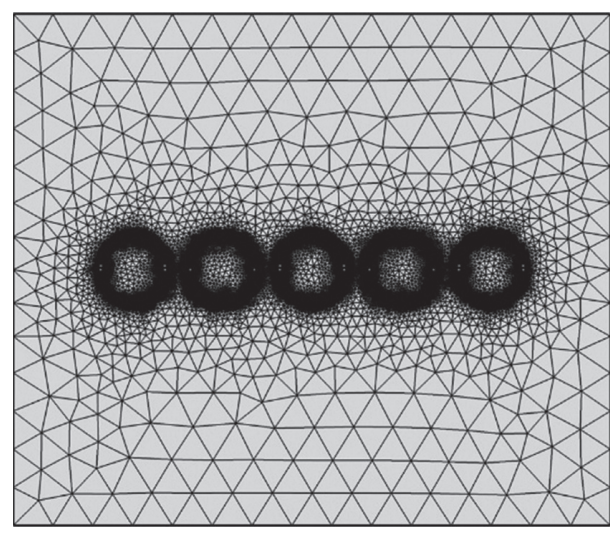

(a)

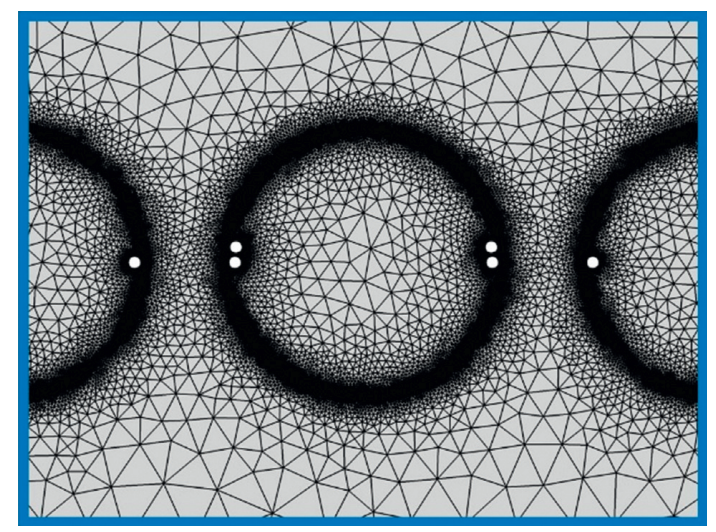

(b)

FIgURE 12: Grid system of Configuration C.

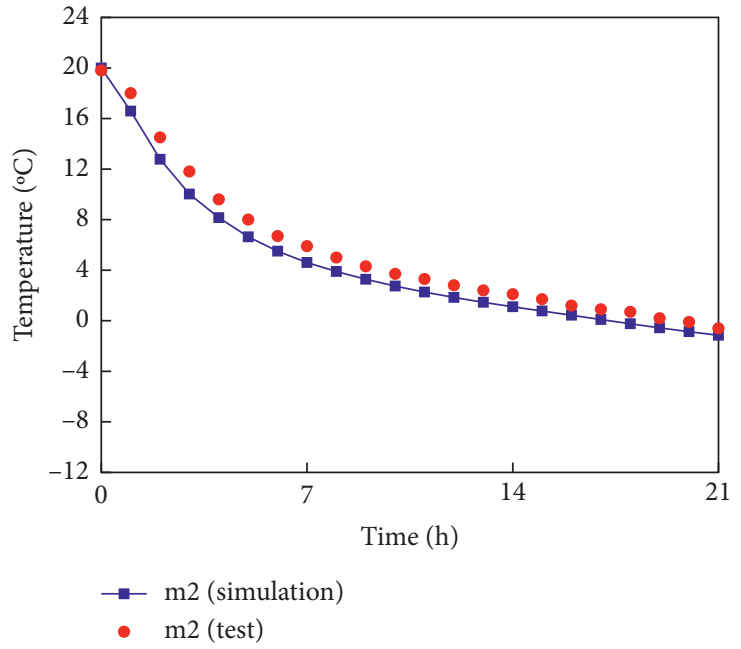

(a)

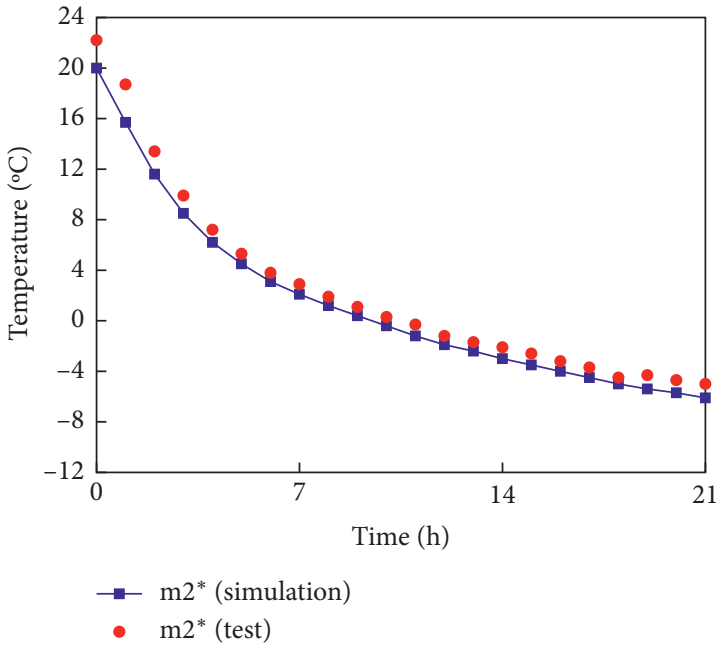

(b)

FIGURE 13: Comparison between simulation data and test data: (a) m2 (Configuration A). (b) m2* (Configuration B).

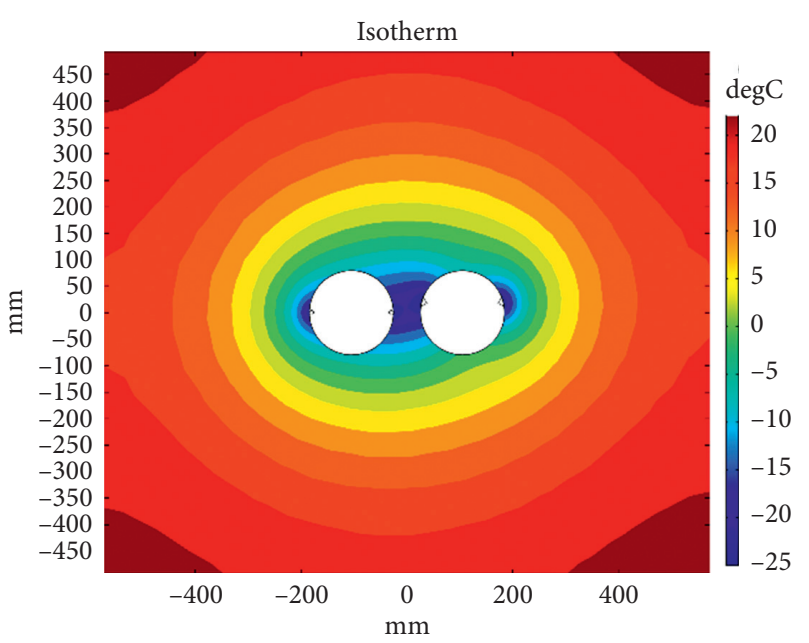

(a)

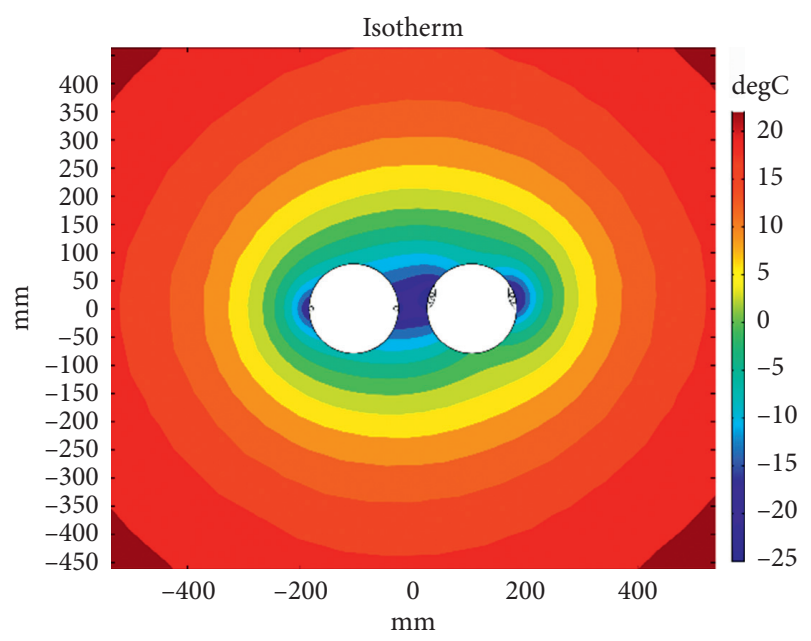

(b)

Figure 14: Distribution of freezing temperature field at $21 \mathrm{~h}$. (a) Configuration A. (b) Configuration B. 


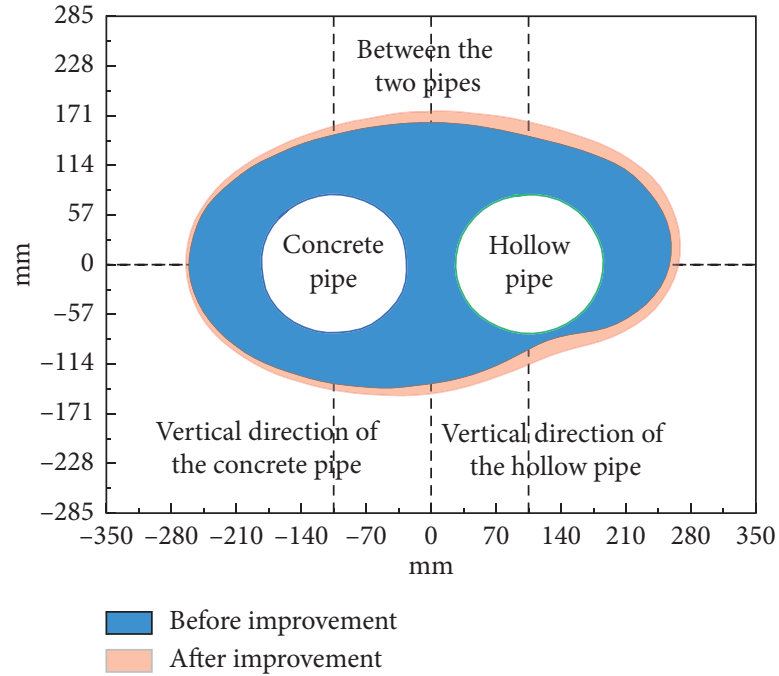

(a)

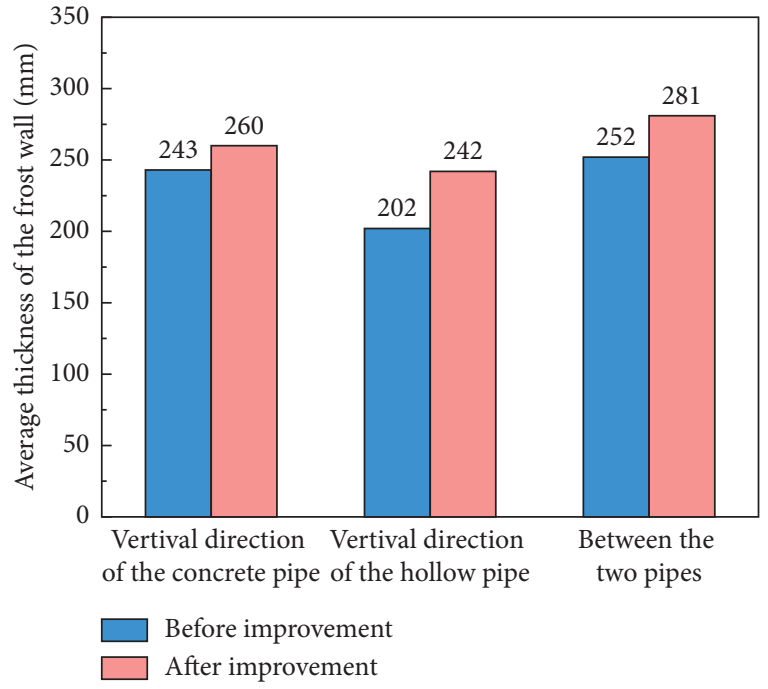

(b)

FIGURE 15: Comparison of the frozen soil wall at different positions at $21 \mathrm{~h}$.

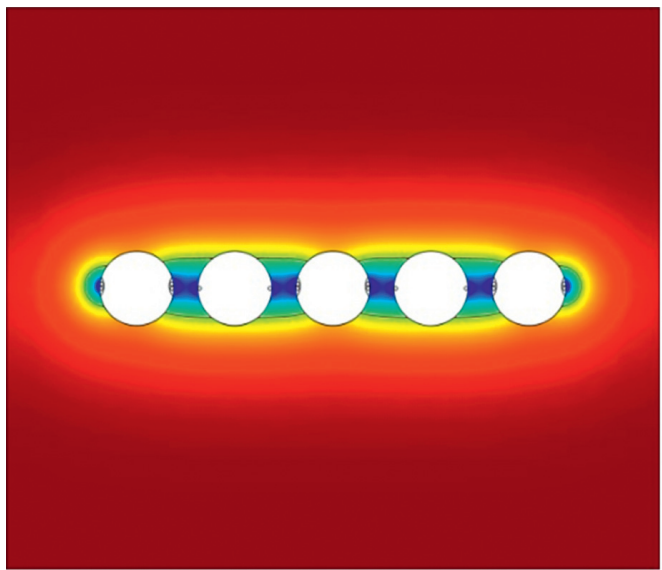

(a)

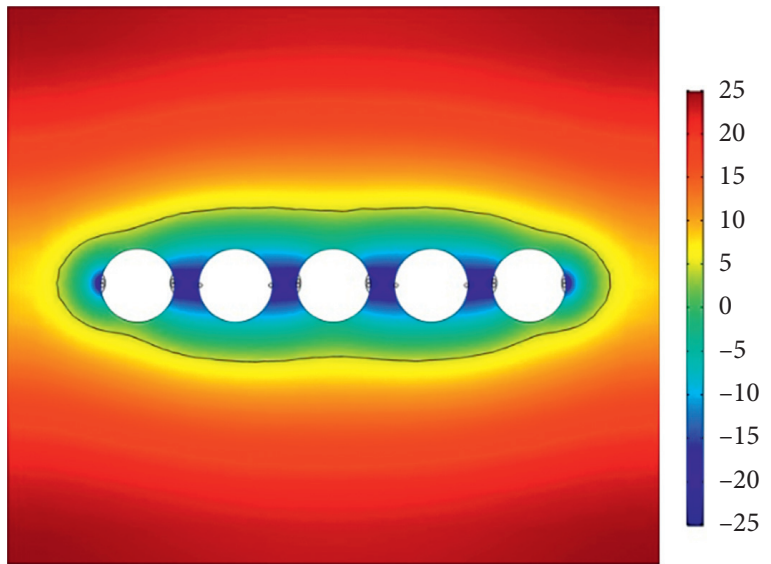

(c)

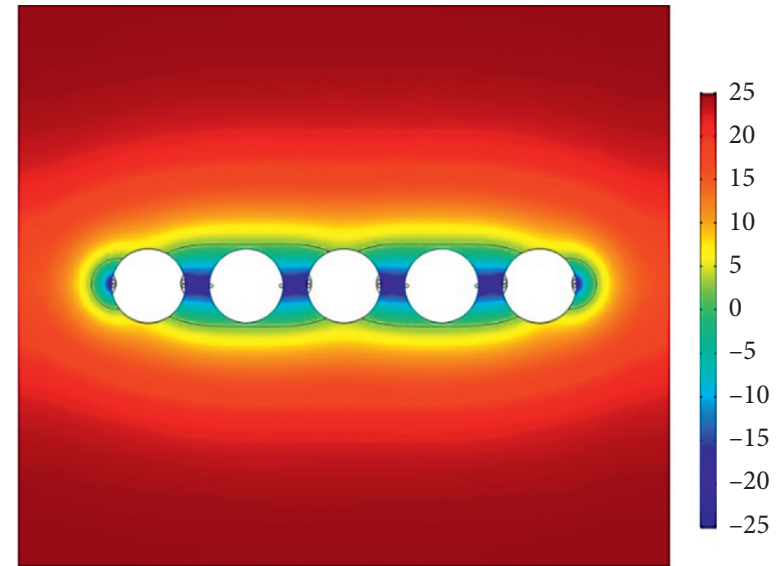

(b)

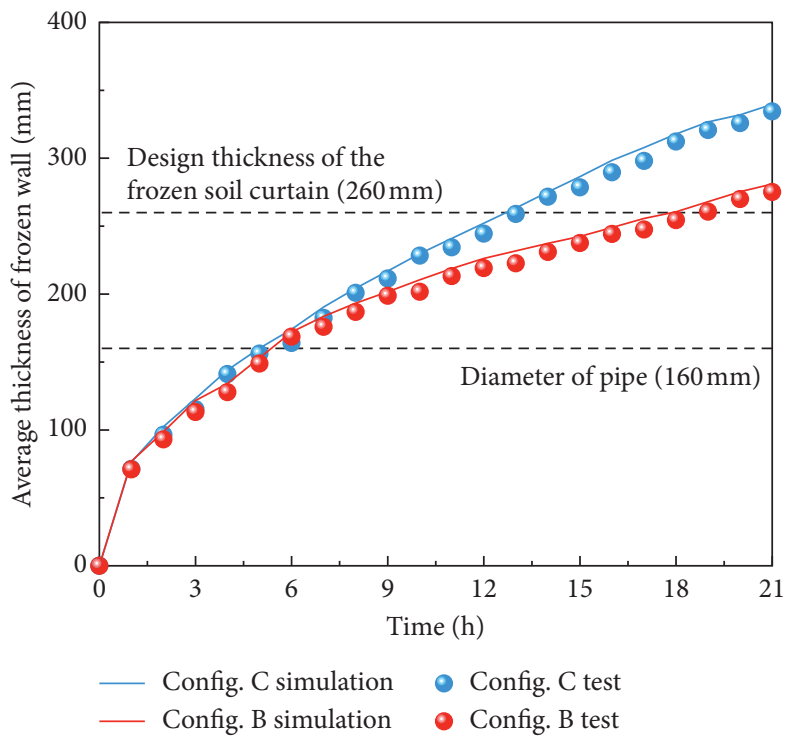

(d)

FIgURe 16: Distribution of the freezing temperature field of Configuration C and curves of the average frozen soil wall thickness: (a) Freezing temperature field at $3 \mathrm{~h}$. (b) Freezing temperature field at $6 \mathrm{~h}$. (c) Freezing temperature field at $21 \mathrm{~h}$. (d) Comparison of the development curves of average frozen wall thickness in Configurations $\mathrm{B}$ and $\mathrm{C}$. 
due to the influences of external factors, such as ground stresses and construction thermal disturbances. The frozen soil wall completely wrapped the concrete pipe at $6 \mathrm{~h}$ (Figure 16(b)), and the temperatures at 15\# and 16\# had reached the freezing point. Some soil on the upper and lower sides of the hollow pipe remained unfrozen, and the average thickness of the frozen soil wall between the pipes was about $174 \mathrm{~mm}$. However, it was still necessary to closely observe the development of the frozen soil wall at the upper and lower contour lines of the hollow pipe to avoid the effects of thermal disturbances. At $21 \mathrm{~h}$ (Figure 16(c)), the range of the frozen soil wall was further expanded, all pipes were wrapped by it, and the contour of it had an uneven shape. At this stage, a "steel pipe-frozen soil curtain" composite structure with better carrying capacity and water sealing performance had been formed. The average thickness of the frozen soil curtain around the concrete pipe $(349.5 \mathrm{~mm})$ was slightly larger than that around the hollow pipe $(336.9 \mathrm{~mm})$; thus, this pipe configuration effectively met the freezing design requirements.

It was evident from Figure 16(d) that the curves of average frozen soil wall thickness in Configurations B and C obtained from numerical simulation were consistent with the test results. At the beginning of the freezing process, the frozen soil walls of Configurations $B$ and $C$ developed rapidly, and the time taken to expand their range to the pipe diameter $(160 \mathrm{~mm})$ was about 5 hours. After 7 hours, the "group pipe effect" became evident in Configuration C, and the development speed was faster, reaching a design thickness of $260 \mathrm{~mm}$ at $13 \mathrm{~h}$ (5 hours earlier than Configuration B). Therefore, by adopting the improved double circular freezing tubes, the freezing effect was further strengthened in the pipe roof structure (Configuration C). Subsequently, the development entered a relatively slower stage. At this time, the thickness of the frozen soil curtain should be monitored precisely, and the formation of excessive frost heave should be reduced through technical means, such as cooling capacity control of the refrigeration system.

\section{Conclusions}

(1) To solve the existing problems of the Gongbei Tunnel Project, an improved design was proposed based on the FSPR. The temperature field distribution characteristics and freezing performances for three different pipe configurations were investigated by scaled model tests and numerical simulations. The improved double circular freezing tubes were easy to manufacture and install, and this approach could solve several practical problems in the actual project, such as profiled freezing tube welding difficulties, refrigerant leakage, and working environment hazards.

(2) The improved results (Configuration B) exhibited a better freezing effect in terms of lower temperature and higher cooling rate and significantly shortened the time required for soil freezing in the test. In comparison to the prototype (Configuration $\mathrm{A}$ ), the average thickness of the frozen wall on the vertical line of the hollow pipe, the vertical line of the concrete pipe, and between two pipes increased by $20 \%, 7 \%$, and $12 \%$, respectively.

(3) Compared with the first two configurations, the "group pipe effect" was more significant in Configuration C; thus, the freezing effect was further improved. Numerical simulation results revealed that a certain thickness of the frozen wall was quickly formed between the pipes at first. Subsequently, the concrete pipe was completely wrapped by frozen soil, and the freezing range then gradually expanded to the hollow pipe. Finally, a composite structure of "pipe roof and frozen soil curtain" with better carrying capacity and water sealing performance had been formed. It was suggested to strengthen the monitoring of frozen soil temperature at the pipe wall in the preliminary stage of the freezing construction process to avoid "thermal disturbances" causing cracks and water flow channels at the interface between the frozen soil and the pipe wall. In the later stage, the thickness of the frozen curtain should be monitored precisely, and the excessive frost heave should be reduced through technical means, such as cooling capacity control.

\section{Data Availability}

The data used to support the findings of this study are available from the corresponding author upon request.

\section{Conflicts of Interest}

The authors declare that there are no conflicts of interest regarding the publication of this paper.

\section{Acknowledgments}

This research was funded by National Natural Science Foundation of China (Grant nos. 51878005 and 51778004).

\section{References}

[1] X. Chen, "Research on combined construction technology for cross-subway tunnels in underground spaces," Engineering, vol. 4, no. 1, pp. 103-111, 2018.

[2] X. Chen, Z. Xu, X. Bao, X. Wang, and Y. Fu, "Challenges and technological breakthroughs in tunnel construction in China," China Journal of Highway and Transport, vol. 33, no. 12, pp. 1-14, 2020.

[3] H. Zhu, W. Ding, Y. Qiao, and X. Wang, "Issues and challenges in urban underground space utilization in China," Earth Science Frontiers, vol. 26, no. 3, pp. 022-031, 2019.

[4] Z. Xiong, H. Lu, M. Wang, Q. Qian, and X. Rong, "Research progress on safety risk management for large scale geotechnical engineering construction in China," Rock and Soil Mechanics, vol. 39, no. 10, pp. 3703-3716, 2018.

[5] H. Zhu, Z. Yang, X. Li, X.-Z Liu, and G.-P. Shen, "Analysis of construction risk for pipe-roofing tunnel in saturated soft soil," Chinese Journal of Rock Mechanics and Engineering, vol. 24, no. S2, pp. 5549-5554, 2005. 
[6] J. Sun, X. F. Yu, M. Sun, and X. Li, "Analysis and prediction on soft ground deformation of a super-large shallow buried "pipe-roofing and box-culvert" jacking project under construction," Rock and Soil Mechanics, vol. 27, no. 7, pp. 1021-1027, 2006.

[7] Y. Li, Y. Zhang, and W. Li, "Research and application of pipe roofing method in soft soil," Chinese Journal of Underground Space and Engineering, vol. 7, no. 5, pp. 962-967, 2011.

[8] X. Guo, H. Zhang, J. Meng, X. Zhang, M. Wang, and Y. Zhu, "Model test to earth pressure distribution on pipe roof of tunnels as pre-supporting system in weak surrounding rock," Chinese Journal of Rock Mechanics and Engineering, vol. 35, no. 6, pp. 1214-1224, 2016.

[9] W. Pan, "Monitoring and analysis of ground settlement during pipe roof construction of pipe-jacking groups in soft soil areas," Chinese Journal of Geotechnical Engineering, vol. 41, no. S1, pp. 201-204, 2019.

[10] X. Chen, "Several key points of artificial ground freezing method and its latest application in China," Tunnel Construction, vol. 35, no. 12, pp. 1243-1251, 2015.

[11] H. Cai, S. Li, Y. Liang, Z. Yao, and H. Cheng, "Model test and numerical simulation of frost heave during twin-tunnel construction using artificial ground-freezing technique," Computers and Geotechnics, vol. 115, pp. 103-155, 2019.

[12] H. Cai, L. Peng, and T. Zheng, "A method for predicting ground surface settlement in the artificial thawing period of tunnel horizontally frozen wall," Rock and Soil Mechanics, vol. 36, no. 12, pp. 3516-3522, 2015.

[13] H. Cai, Z. Liu, S. Liu, and T. Zheng, "Improved analytical prediction of ground frost heave during tunnel construction using artificial ground freezing technique," Tunnelling and Underground Space Technology, vol. 92, 2019.

[14] H. Song, H. Cai, Z. Yao, C. Rong, and X. Wang, "Finite element analysis on 3D freezing temperature field in metro cross passage construction," Procedia Engineering, vol. 165, pp. 528-539, 2016.

[15] Y. Mei, L. Zhao, D. Zhou, J. Liu, J. Zhu, and J. Zhu, “Application of AGF in underground excavation construction of water-rich sand layer," China Railway Science, vol. 41, no. 4, pp. 1-10, 2020.

[16] J. Yu, Y. Cheng, R. Jia et al., "Option demonstration for the Gongbei tunnel at the Zhuhai link of the Hong Kong-ZhuhaiMacau bridge," Modern Tunnelling Technology, vol. 49, no. 1, pp. 119-125, 2012.

[17] J. Liu, Y. Cheng, X. Guo et al., "Design for a super-shallow large-section double-level tunnel in complex conditions underneath sensitive buildings," Modern Tunnelling Technology, vol. 51, no. 5, pp. 174-179, 2014.

[18] X. Hu and S. She, "Study of freezing scheme in freeze-sealing pipe roof method based on numerical simulation of temperature field," in Proceedings of the International Conference on Pipeline and Trenchless Technology, pp. 19-22, Wuhan, China, October 2012.

[19] X. Hu and T. Fang, "numerical simulation of temperature field at the active freeze period in tunnel construction using freezesealing pipe roof method," in Proceedings of the Geo-Shanghai 2014, pp. 731-741, Shanghai, China, May 2014.

[20] Y. Wang, "Mechanical property analysis of steel pipe-frozen soil composite structure in freeze-sealing pipe roof method," Master's Thesis, Tongji University, Shanghai, China, 2013.

[21] X. Hu, H. Ren, J. Chen et al., "Model test study of the active freezing scheme for the combined pipe-roof and freezing method," Modern Tunneling Technology, vol. 51, no. 5, pp. 92-98, 2014.
[22] X. Hu, X. Guo, Q. Wang et al., "Field test study on freezing technology of freeze-sealing pipe roof," Tunnel Construction, vol. 35, no. S2, pp. 1-7, 2015.

[23] H. Ren, X. Hu, J. Chen et al., "Study on freezing effect and operation of profiled enhancing freezing-tube in freezesealing pipe roof," Tunnel Construction, vol. 35, no. 11, pp. 1169-1175, 2015.

[24] X. Ji, B. Long, and X. Yang, "3D simulation analysis of closely jacking pipe in pipe curtaining pre-reinforcement," Chinese Journal of Underground Space and Engineering, vol. 12, no. S1, pp. 267-274, 2016.

[25] Y. Kang, Q. Liu, Y. Cheng et al., "Combined freeze-sealing and New Tubular Roof construction methods for seaside urban tunnel in soft ground," Tunnelling and Underground Space Technology, vol. 58, pp. 1-10, 2016.

[26] Y. Lu, H. Zhang, L. Wei et al., "Numerical simulation of temperature field in freezing process with pipe roof freezing method," Railway Engineering, vol. 57, no. 12, pp. 52-54, 2017.

[27] J. Zhang, P. Shi, and J. Pan, "Study of ground frost heave control technology used in Gongbei tunnel constructed by pipe roof and ground freezing method," Tunnel Construction, vol. 38, no. 5, pp. 809-817, 2018.

[28] H. Ren, X. Hu, Z. Hong et al., "Experimental study on active freezing scheme of freeze-sealing pipe roof used in ultrashallow buried tunnels," Chinese Journal of Geotechnical Engineering, vol. 41, no. 2, pp. 320-328, 2019.

[29] W. Long, C. Rong, Y. Duan et al., "Numerical calculation of temperature field of freeze-sealing pipe roof method in Gongbei tunnel," Coal Geology \& Exploration, vol. 48, no. 3, pp. 160-168, 2020.

[30] K. Guo, Y. Duan, and Y. Ding, "Numerical simulation of temperature field of tube-curtain freezing method for shallow buried tunnel," Journal of Anhui University of Science and Technology, vol. 39, no. 2, pp. 63-68, 2019.

[31] G. X. Cui and Q. G. Lu, "Study on law of thickness and deformation of ice-wall by using models," Journal of China Coal Society, vol. 17, pp. 37-47, 1992.

[32] H. Cheng, Z. Yao, J. Zhang et al., "A model test study on the effect of freeze heaving and thaw subsidence for tunnel construction with artificial horizontal ground freezing," China Civil Engineering Journal, vol. 40, no. 10, pp. 80-85, 2007.

[33] R. N. Taylor, "Geotechnical centrifuge technology," Blackie Academic \& Professionalpp. 273-280, CRC Press, London, UK, 1st edition, 1994.

[34] H. Cai, H. Cheng, Z. Yao et al., "Numerical analysis of ground displacement due to orthotropic frost heave of frozen soil in freezing period of tunnel," Chinese Journal of Rock Mechanics and Engineering, vol. 34, pp. 1667-1676, 2015.

[35] Y. Lai, S. Liu, Z. Wu et al., "Approximate analytical solution for temperature fields in cold regions circular tunnels," Cold Regions Science and Technology, vol. 34, pp. 43-49, 2002.

[36] X.-D. Hu, T. Fang, and Y.-G. Han, "Mathematical solution of steady-state temperature field of circular frozen wall by singlecircle-piped freezing," Cold Regions Science and Technology, vol. 148, pp. 96-103, 2018.

[37] COMSOL Multiphysics Reference Manual, COMSOL AB, Stockholm, Sweden, 2018, http://cn.comsol.com/. 